\title{
Combining social network analysis and agent-based modelling to explore dynamics of human interaction: A review
}

\author{
Meike Will ${ }^{1 *}$, Jürgen Groeneveld ${ }^{1,2,3}$, Karin Frank ${ }^{1,3,4}$, Birgit Müller ${ }^{1}$ \\ ${ }^{1}$ Helmholtz Centre for Environmental Research - UFZ, Dept. of Ecological Modelling, Leipzig, Germany \\ 2 TU Dresden, Institute of Forest Growth and Forest Computer Sciences, Tharandt, Germany \\ ${ }^{3}$ German Centre for Integrative Biodiversity Research (iDiv) Halle-Jena-Leipzig, Germany \\ ${ }^{4}$ University of Osnabrück, Institute of Environmental Systems Research (USF), Osnabrück, Germany
}

\begin{abstract}
Agent-based modelling (ABM) and social network analysis (SNA) are both valuable tools for exploring the impact of human interactions on a broad range of social and ecological patterns. Integrating these approaches offers unique opportunities to gain insights into human behaviour that neither the evaluation of social networks nor agent-based models alone can provide. There are many intriguing examples that demonstrate this potential, for instance in epidemiology, marketing or social dynamics. Based on an extensive literature review, we provide an overview on coupling ABM with SNA and evaluating the integrated approach. Building on this, we identify current shortcomings in the combination of the two methods. The greatest room for improvement is found with regard to (i) the consideration of the concept of social integration through networks, (ii) an increased use of the coevolutionary character of social networks and embedded agents, and (iii) a systematic and quantitative model analysis focusing on the causal relationship between the agents and the network. Furthermore, we highlight the importance of a comprehensive and clearly structured model conceptualization and documentation. We synthesize our findings in guidelines that contain the main aspects to consider when integrating social networks into agent-based models.
\end{abstract}

\section{Keywords}

agent-based modelling; social network analysis; human behaviour; review

\section{Introduction}

Many of the challenges society is facing today are not determined by individualistic action, but by behaviour embedded in complex networks of personal relationships, communities and markets. Climate change, for example, can only be tackled if people change their everyday behaviour, which strongly depends on actions of their surroundings (Kjeldahl \& Hendricks, 2018; Senbel et al., 2014). Connections in a digitalized world allow communication independent of physical distances, but also bear specific risks (Kaplan \& Haenlein, 2010; PastorSatorras \& Vespignani, 2001). Epidemics such as measles and Ebola spread more easily the more people resist proper prevention (Andre et al., 2008; Chowell \& Nishiura, 2014), and global markets are largely dominated by the interaction of customers, suppliers and businesses (Garlaschelli \& Loffredo, 2005; Gereffi, 1999). To understand these complex social processes of our time, it is essential that research draws attention both to

\footnotetext{
Correspondence:

Contact M. Will at meike.will@ufz.de
}

Cite this article as:

Will, M., Groeneveld, J., Frank, K. \& Müller, B.

Combining social network analysis and agent-based modelling to explore dynamics of human interaction: A review

Socio-Environmental Systems Modelling, vol. 2, 16325, 2020, doi:10.18174/sesmo.2020a16325

This work is licensed under a Creative Commons Attribution-NonCommercial 4.0 International License. 
human behaviour and to the structure of social networks and their dynamics. A promising approach to address these two aspects is the combination of social network analysis (SNA) and agent-based modelling (ABM).

Analysing social structure in a formalized way has attracted interest from a wide range of social and behavioural disciplines (Borgatti et al., 2009; Butts, 2009). As an approach to rigorously quantifying patterns of relations between social entities by means of formally defined graph-theoretic methods, SNA can contribute to the understanding of various social phenomena (Emirbayer \& Goodwin, 1994; Scott, 2011; Wasserman \& Faust, 1994). On the other hand, ABM, too, has proven to be a valuable approach to address the complex task of analysing the interplay between individuals or groups (Gilbert, 2008; Squazzoni, 2010). Agent-based models are process-based simulation tools that can capture feedbacks between the behaviour of heterogeneous agents and their surroundings. In this context, agents can be entities such as humans, households, firms or institutions (Railsback \& Grimm, 2012). On a micro-level, agents act interdependently according to prescribed rules and adjust their behaviour to the current state of themselves, of other agents and of the environment (Bonabeau, 2002; Railsback \& Grimm, 2012). On the macro-level, emergent patterns and dynamics arise from the aggregated individual behaviours and the interactions between the agents (Kiesling et al., 2012).

As the interaction of agents with one another can be mapped to the concept of nodes and links established in the field of network science, a combination of both approaches can be easily achieved. Embedding networks in ABM makes it possible to define the set of agents with which a focal agent interacts not exclusively via spatial relationships, as in virtually all spatial agent-based models, but via the agent's social network, i.e. a (dynamic) set of other agents (Railsback \& Grimm, 2012). Since individual behaviour and network structure are largely intertwined, social systems often show nonlinear and unpredictable behaviour. Integrating social networks in computer simulations such as ABM helps to understand these processes (Bonabeau, 2002; Squazzoni et al., 2014). Furthermore, $A B M$ can complement the sampling bias that is common in network structures mapped by empirical approaches of the social sciences (Costenbader \& Valente, 2003; Stumpf et al., 2005). As complete network data is rare, a comprehensive picture of the whole node-ties landscape is often missing. Computational modelling can be used as a "virtual lab" to explore systems in space and time and to test hypotheses about causal relationships (Carley, 2009). A systematic combination of these theory-driven approaches with the empirically-driven aspects of network science thus helps to fill gaps that both approaches have and opens many possibilities to investigate human behaviour that neither the evaluation of social networks nor agent-based models alone can provide.

The potential to explore the dynamics of social networks with agent-based models has been recognized in various disciplines of contemporary research. Examples can be found, among others, in the context of epidemiology (Eubank et al., 2004; Verelst et al., 2016), marketing (Kiesling et al., 2012; Rai \& Henry, 2016; Rand \& Rust, 2011) or social dynamics (Castellano et al., 2009; Macy \& Willer, 2002; Squazzoni et al., 2014). Despite this broad range of application, the potential to combine both approaches is far from being exhausted, as will be shown in this review.

The aim of this paper is threefold: (i) bring together different research streams, in which ABM is coupled with social networks, to enable an increased methodological cross-fertilization between disciplines, which has so far been hardly realized, (ii) detect current limitations in the combination of the two methods, and (iii) propose guidelines that provide a basis for a comprehensive and clearly structured model set-up which supports the application of a systematic and quantitative analysis of social networks in agent-based models. The guidelines take full advantage of combining both approaches to explore human interaction and are meant to serve modellers in future projects.

\section{Methods}

To reveal the diverse range of applications and identify key challenges when combining agent-based models and social networks, we provide a review of a selection of exemplary studies. We evaluated 54 publications from different fields to gain an overview of the current usage of social networks in agent-based models and to find possible gaps in their implementation and analysis. Our search was limited to agent-based and multi-agent models, a term often used as a synonym for agent-based models, where it is explicitly stated that social networks are integrated (see Supplementary Material A for details). We are aware that especially in the area of network research there are other terminologies (e.g. network model or game-theoretic model) that refer to similar 
concepts and do not fall under our search restrictions. However, we believe that ABM is a reasonable umbrella term for all these approaches and that most results are transferable. Furthermore, we did not aim to conduct a systematic review of all sampled models, but tried to cover the most recent and, according to the number of citations, the most established results (see Supplementary Material A for the selection criteria and Supplementary Material B for a detailed classification of the reviewed models).

As an outcome of this investigation, we elaborate in the remainder of the review on the potential of linking ABM with social networks. We highlight three areas of common shortcomings and offer opportunities for improvement. First, we focus on the role of social networks in agent-based models in terms of their purposes. Second, we distinguish ways of integrating networks in agent-based models; and third, we emphasize currently used as well as potentially more beneficial approaches for model analysis. Table 1 summarizes all aspects on the classification for social networks in ABM that will be revealed in the course of the review. To address the observed deficiencies in terms of comprehensive and clearly structured model conceptualization and evaluation, we conclude with proposing guidelines covering all aspects that need to be considered for sound modelling and systematic analysis of social networks.

Table 1: Summary of classification aspects for social networks in ABM used in this review with reference to the respective sections that address these aspects

\begin{tabular}{|c|c|c|c|c|}
\hline \multirow{3}{*}{$\begin{array}{l}\text { Purpose } \\
\text { (section 3.1) } \\
\\
\text { Network integration } \\
\text { (section 3.2) }\end{array}$} & \multicolumn{4}{|c|}{ Levels } \\
\hline & \multicolumn{2}{|c|}{$\begin{array}{l}\text { Diffusion: Links between agents in a network } \\
\text { serve as channels for transfer of material or } \\
\text { non-material resources. }\end{array}$} & \multicolumn{2}{|c|}{$\begin{array}{l}\text { Social integration: Social ties represent } \\
\text { integration of actors in a group; agent's } \\
\text { network position provides social capital } \\
\text { which leads to achievements, success or } \\
\text { power. }\end{array}$} \\
\hline & $\begin{array}{l}\text { Endogenous: Network } \\
\text { topology evolves during the } \\
\text { simulation based on } \\
\text { individual decisions of } \\
\text { agents and further impacts } \\
\text { through the environment. }\end{array}$ & $\begin{array}{l}\text { Exogenous: } \\
\text { topology is } \\
\text { fixed during } \\
\text { focus on how } \\
\text { structure affe } \\
\text { agents } \\
\text { dynamics. }\end{array}$ & $\begin{array}{l}\text { Network } \\
\text { mposed and } \\
\text { he simulation; } \\
\text { ocial network } \\
\text { ts state of the } \\
\text { d system }\end{array}$ & $\begin{array}{l}\text { Co-evolutionary: Feedback } \\
\text { loop between changing the } \\
\text { states of agents through } \\
\text { their interaction and } \\
\text { adapting the topology of the } \\
\text { network leads to } \\
\text { dynamically evolving } \\
\text { network. }\end{array}$ \\
\hline $\begin{array}{l}\text { Types of analysis } \\
\text { (section } 3.3 \text { ) }\end{array}$ & $\begin{array}{l}\text { Agent-centric: Effect of } \\
\text { parameters not related to } \\
\text { the network. }\end{array}$ & $\begin{array}{l}\text { Network-cen } \\
\text { link propert } \\
\text { network mea }\end{array}$ & $\begin{array}{l}\text { ic: Effect of } \\
\text { es or global } \\
\text { ures. }\end{array}$ & $\begin{array}{l}\text { Structurally explicit: Causal } \\
\text { relation between agents } \\
\text { and network structure, } \\
\text { effect of local network } \\
\text { measures. }\end{array}$ \\
\hline
\end{tabular}

\section{Potential of linking ABM with social networks}

The unmatched potential to address the dynamics of social interaction through a coupled social network and ABM approach has been recognized in various disciplines of contemporary research. By reviewing the selected publications, we identified three main areas of application, which are not without overlaps: epidemiology, marketing and social dynamics. To reveal the full spectrum of social networks in these contexts, we illustrate different (i) purposes, (ii) ways of network integration, and (iii) types of analysis of social networks in ABM and give recommendations on how to overcome common shortcomings. For all approaches in the following sections, we include key examples from the reviewed literature to illustrate different possible realizations and their suitability.

\subsection{Purpose}

Social networks in ABM have two main purposes: diffusion and social integration (Borgatti \& Foster, 2003; Goldstone \& Janssen, 2005; Granovetter, 2005; Klabunde \& Willekens, 2016; Macy \& Willer, 2002). The relevance of both is addressed separately in the following two sections. 


\subsubsection{Diffusion}

If diffusion is the model purpose, the linkages between agents in a network serve as channels for transfer of material (e.g. goods) or non-material resources (e.g. information). Implementing connections between agents allows to model how new ideas, practices or diseases spread within and between communities through interpersonal contacts (Valente, 2005; Wasserman \& Faust, 1994).

In epidemiology, ABM with integrated social networks is widely used to overcome the unrealistic assumptions of homogeneous mixing used in traditional models of disease spread based on differential equations (Eubank et al., 2004; Rahmandad \& Sterman, 2008). As the transmission of a disease is directly influenced by the behaviour of individuals, social networks are not only included in the models to serve as a channel for the diffusion of epidemics but they allow the direct incorporation of social factors such as the propensity to vaccinate (Fu et al., 2011) or hygiene compliance (Hornbeck et al., 2012) that can influence health outcomes (El-Sayed et al., 2012; Verelst et al., 2016).

Marketing research addresses the spread of non-material processes when dealing with the diffusion of innovations (Kiesling et al., 2012; Peres et al., 2010). Agents exchange information with their peers which influences their decision towards a new product (Amini et al., 2012; Bohlmann et al., 2010; Goldenberg et al., 2007; Haenlein \& Libai, 2013; Hu, et al., 2018; Janssen \& Jager, 2001, 2003; Libai et al., 2013; Negahban \& Smith, 2018) or technology such as sustainable mobility (Huétink et al., 2010), solar photovoltaics (Pearce \& Slade, 2018; Wang et al., 2018), water conservation (Rasoulkhani et al., 2018), smart metering (Zhang \& Nuttall, 2011), flood prevention measures (Erdlenbruch \& Bonte, 2018) or innovations like autonomous vehicles (Talebian \& Mishra, 2018).

Similar research questions are addressed with respect to social dynamics (Bianchi \& Squazzoni, 2015; Macy \& Willer, 2002). In this field, the main focus is on social influence on the dissemination of attitudes (e.g. regarding sustainable energy use (Moglia et al., 2018; Niamir et al., 2018) or organic farming (Kaufmann et al., 2009)), culture (Flache \& Macy, 2011; Keijzer et al., 2018), language (Ke et al., 2008; Lou-Magnuson \& Onnis, 2018), opinions (Biondo et al., 2018; Lu et al., 2009; Piedrahita et al., 2018), trends (Schlaile et al., 2018; Weng et al., 2012) or information (Chareunsy, 2018; Frank et al., 2018).

\subsubsection{Social integration}

Interaction between agents, however, does not necessarily involve a direct exchange. Apart from being channels for transfer, social ties also represent the social integration of actors in a group. These connections to others provide possibilities and constraints for action (Bianchi \& Squazzoni, 2015; Borgatti \& Foster, 2003; Granovetter, 1985; Macy \& Willer, 2002; Smith \& Christakis, 2008). The network structure can be seen as a form of coordination which enables collective action, self-organization and cross-scale support (Cumming, 2016; Rockenbauch \& Sakdapolrak, 2017). An agent's network position provides social capital which leads to certain achievements, success or power. Examples include the evolution of cooperation based on familiarity (Son \& Rojas, 2011), similarities (Hadzibeganovic et al., 2018) or trust (Bravo et al., 2012; Growiec et al., 2018; Laifa et al., 2018). Additionally, a social environment can provide existential security (Gore et al., 2018) or can support people to promote an activity (Garcia et al., 2018).

\subsubsection{Recommendations}

We observe that ABM most often addresses the concept of networks as channels for transfers and considers social integration only rarely. We want to underline that the two different purposes of networks, however, both have their justification and want to encourage modellers to apply the concept of social integration which is one of the main thrusts of SNA in agent-based simulations.

\subsection{Network integration}

\subsubsection{Exogenously imposed and endogenously emerging networks}

The critical specification for networks in agent-based models is whether their structure is exogenously imposed or endogenously emerging (Bruch \& Atwell, 2015; Jackson, 2010; Macy \& Willer, 2002; Namatame \& Chen, 2016). In the first case the network structure is fixed and the focus is on how social network structures affect 
the state of the agents and system dynamics (Figure 1a). The vast majority of the models assessed in this review focuses on this approach.

On the other hand, networks can also emerge based on predefined rules in the model. In this case, agents are aware of the impacts of each connection and decide whether they establish relations with other agents, depending on the gains these links provide (Figure 1 b). In established network formation models such as random networks (Erdős \& Rényi, 1959), small-world networks (Watts \& Strogatz, 1998) or scale-free networks (Albert \& Barabási, 2002), the formation rules are not necessarily appropriate to describe sociological questions (Flache \& Snijders, 2008). Endogenously evolving networks in agent-based models of social networks enable the integration of individual decisions of agents and further impacts through the environment in the formation process and can therefore be used to investigate which structures are likely to emerge in certain contexts. Furthermore, ABM allows to analyse the effect of agents' knowledge of the network on the choice of connections. Partial or imperfect information on existing and possible connections induces agents to create, maintain or strategically invest in their ties. Examples of network formation can be found mostly in context of social dynamics and include friendship selection in secondary schools (Fetta et al., 2018), relationships based on similar attitudes (Neal \& Neal, 2014) or creation of urban networks due to spatial closeness of agents' residential locations and workplaces (Zhuge et al., 2018).

a. Dynamics on exogenously imposed network
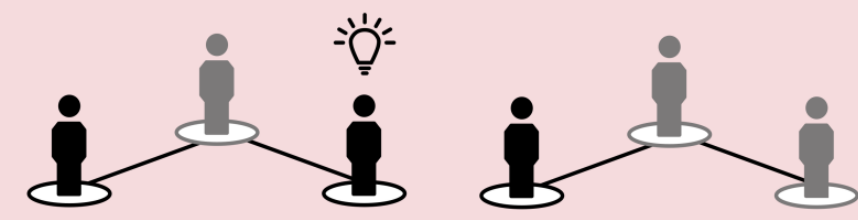

c. Co-evolutionary network:

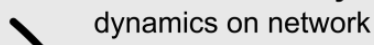

affect network formation

and vice versa

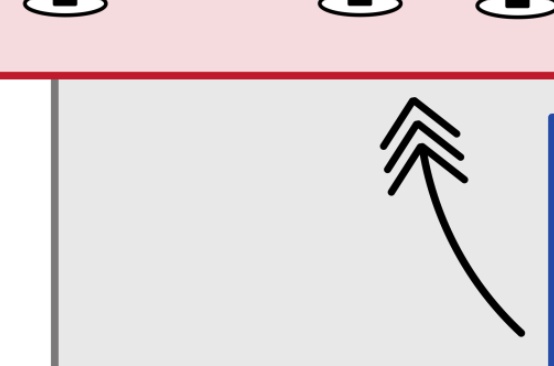

b. Endogenous network formation
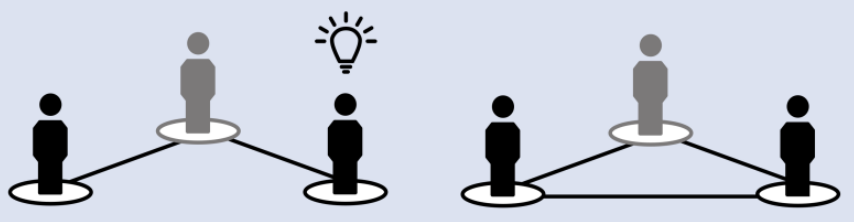

Figure 1 Exogenous, endogenous and co-evolutionary networks in agent-based models with social networks. a. Exogenous network: Social networks enable an appropriate representation of the social interaction between agents. The model dynamics are determined by the interaction of agents linked in an exogenously imposed network which is fixed during the simulation. Here, the focal agent (marked with a bulb) decides to change its state (black to grey) based on the current status of the agents it is linked to. b. Endogenous network: Agent-based models allow the integration of individual behaviour and environmental influences in models of network formation. Links between agents emerge and disappear, but the states of the agents do not necessarily change. Here, the focal agent decides to establish a new link to another agent. c. Co-evolutionary network: The combined approach of both aspects takes into account the feedback loop between state of agents and topology. Agents change their state according to their network connections and their network connections according to their state. Figure adapted from Gross \& Blasius (2008).

\subsubsection{Co-evolutionary networks}

Models considering both endogenous network formation and a dynamic update of the state of the agents depending on the network and vice versa are often called co-evolutionary network models (Gross \& Blasius, 2008) (Figure 1c). The incorporation of the feedback loop between changing the states of agents through their interaction and adapting the topology of the network (i.e. the arrangement of nodes representing agents and links connecting them) through link formation and dissolution combines the advantages of pure network models and the modelling of human behaviour in agent-based models. We observed, however, that this has rarely been 
used in $A B M$ so far. Examples for co-evolutionary networks comprise agents that add or remove links to maximize the information they can gain from their acquaintances (Frank et al., 2018; Lozano et al., 2018; Moradianzadeh et al., 2018; Phan \& Godes, 2018), to establish monogamous mating relationships (Simão \& Todd, 2002), to express their dissatisfaction within a cooperation (Bravo et al., 2012) or if the trust between agents has vanished due to offenses between neighbours (Laifa et al., 2018). Additionally, modified spatial configurations that emerge from the behaviour of the agents (e.g. migration decisions (Fu \& Hao, 2018)) or the appearance and disappearance of additional agents due to birth and death (Hadzibeganovic et al., 2018) can lead to changes in the network structure.

\subsubsection{Recommendations}

The choice of a suitable approach for network integration depends, apart from the research question at hand and the availability of data, largely on the time scale on which the relevant processes take place (Figure 2). Both the network structure and the interaction of the agents can change slowly or quickly (for an overview on the concept of slow and fast variables see e.g. Walker et al., 2012). A network that slowly adapts to the actions of the agents can be considered constant, i.e. it can be determined by fixed exogenously imposed structures. In cases where connections between agents change rapidly but their states adjust slowly, networks form endogenously without affecting the internal characteristics of the agents. If both processes run fast, coevolutionary networks are the appropriate method of choice. As many social connections change over time, this allows adopting concepts of dynamic social networks observed in reality for connections in agent-based models. We strongly recommend that modellers carefully determine the relevant time scales of network and agent dynamics in the specific cases to capture cross-fertilization between network topology and agent behaviour if needed. In situations in which either only the causes or only the consequences of networks are to be investigated, however, the use of endogenously emerging or exogenously imposed structures, respectively, is equally appropriate.

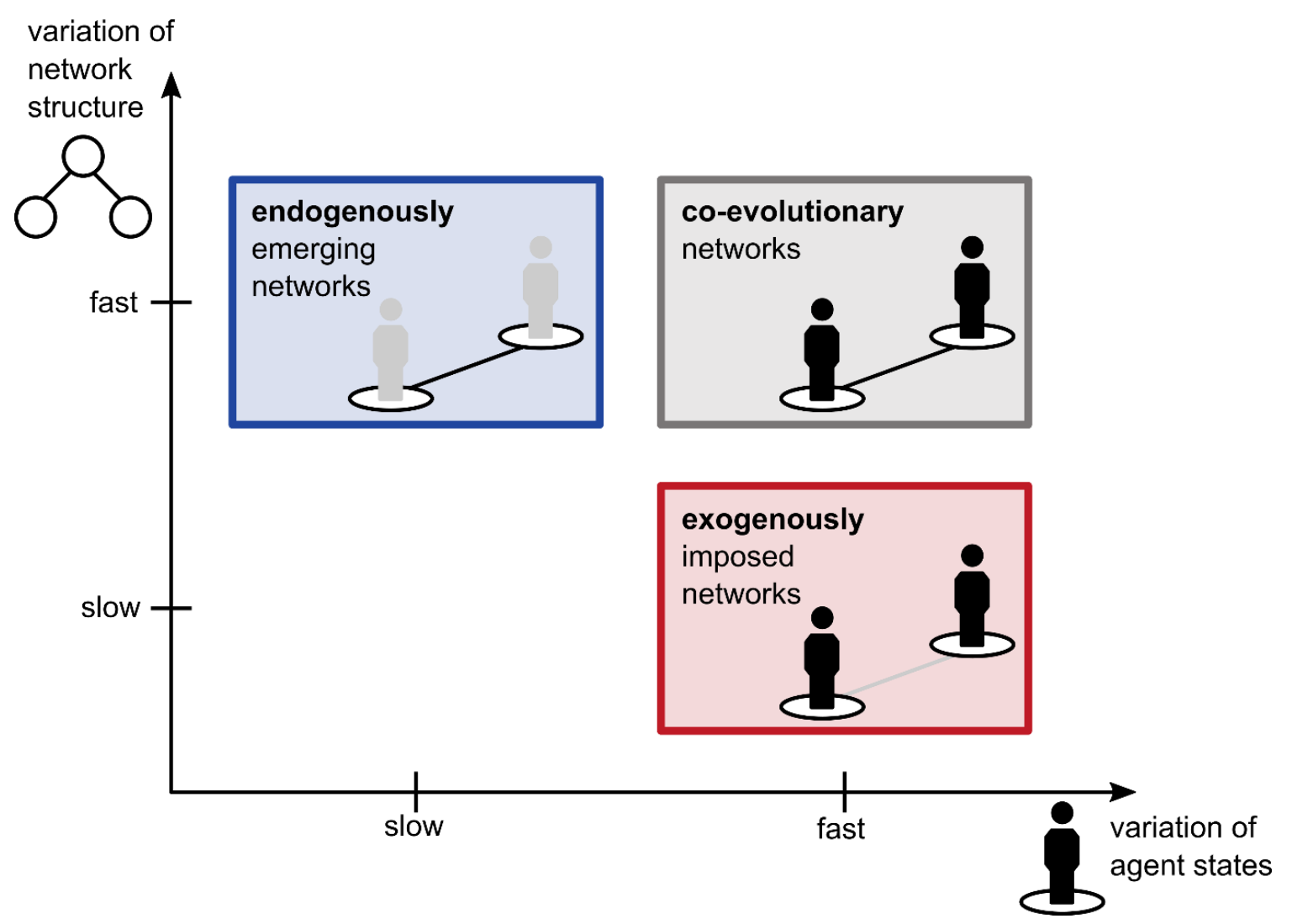

Figure 2: Time scales of variation of network structure and agent states and adequate ways of integrating social networks in ABM. Fixed exogenously imposed networks are suitable if the states of the agents adapt rapidly but changes on the network structure are slow. Endogenously emerging networks capture situations with fast network changes and slowly adjusting agent states. In co-evolutionary networks both processes, variation of network structure and agent states, run fast. 


\subsection{Types of analysis}

Understanding overarching patterns that emerge from assumptions and model rules at the individual level is the key challenge in interpreting the outcomes of agent-based models. We distinguish three approaches to assessing social networks in agent-based models with increasing emphasis on structural characteristics: (i) agent-centric, (ii) network-centric, and (iii) structurally explicit analysis. Figure 3 illustrates all three types of analysis exemplarily. These distinctions mainly apply to exogenously imposed and co-evolutionary networks, since the analysis of models dealing with endogenous network formation is always network-centric. However, driving mechanisms behind endogenous network formation can be classified similarly.

\section{a. agent-centric}

1. Reference state

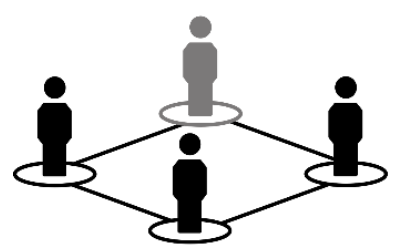

2. Varying agent state

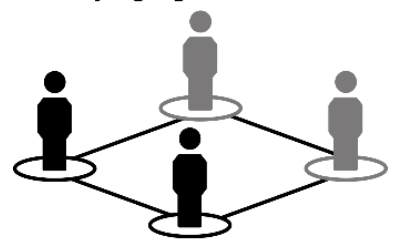

3. Varying external influences

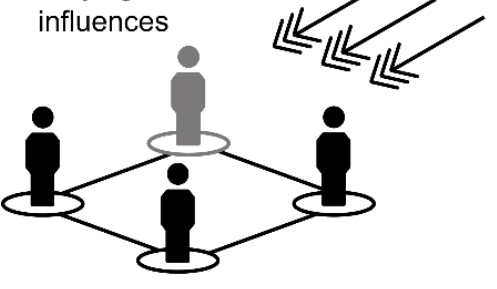

b. network-centric

1. Reference state

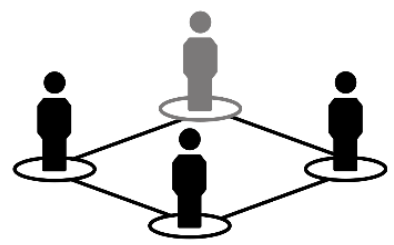

2. Varying network density

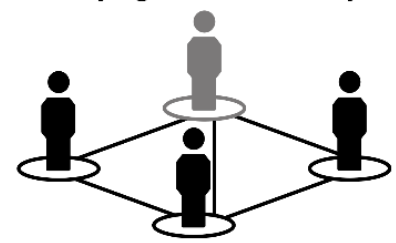

3. Varying network size

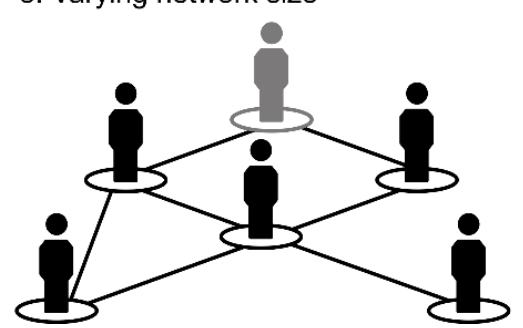

c. structurally explicit

1. Highly connected agent as innovator

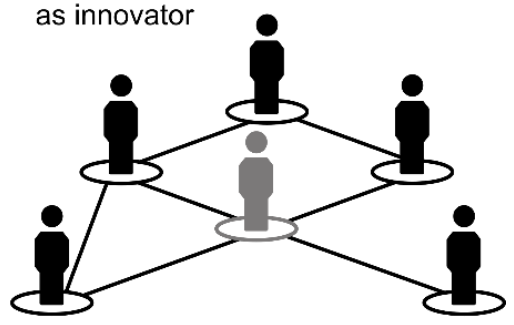

2. Loosely connected agent as innovator

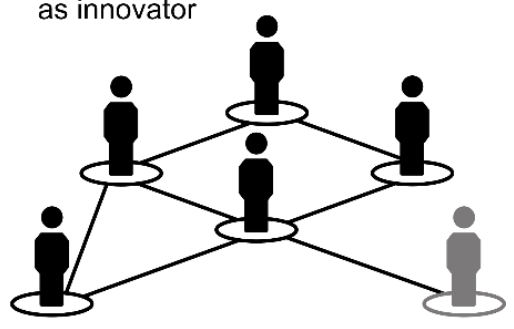

Figure 3: Agent-centric analysis, network-centric analysis, and structurally explicit analysis of social networks in agent-based models. a. Agent-centric analysis: The network plays an important role in the interaction between agents, but different model outcomes are obtained by varying input parameters that are not related to the network itself, such as agent states (1,2), which here are represented by the agent colours, or external influences such as policies (3). b. Network-centric analysis: Agent states are kept constant and the focus is on the impact of modifications at the network level such as varying initial network density $(1,2)$ or size (3). c. Structurally explicit analysis: Model outcomes are assessed not only based on agent or network properties but depend on the location of specific agents in the network. The example shows the initial condition for an innovation to spread (grey colour) for two different scenarios: highly connected agent as innovator (1) and loosely connected agent as innovator (2).

\subsubsection{Agent-centric analysis}

Topics that require agent-centric analysis cover cases where the network plays an important role in the interaction between agents, but the effect of its structure on model results does not need to be explicitly addressed. Figure $3 a$ shows a stylized representation of the initial state of a diffusive system. Input parameters that are not related to the network itself, such as agent states, e.g. the number of black and grey agents, or external influences, e.g. policies, can have effects on the outcome, i.e. how many agents are of grey state at the end of the simulation. Examples from the literature include the comparison of agent properties like variable adoption thresholds (Bohlmann et al., 2010) or group identification of agents (Frank et al., 2018), or the inclusion of external influences such as policies accompanying the introduction of new products (Amini et al., 2012; Negahban \& Smith, 2018), influencing risk prevention of individuals (Erdlenbruch \& Bonte, 2018), mitigating influenza pandemics (Davey et al., 2008; Perlroth et al., 2010) or encouraging the transformation towards 
sustainable behaviour (Kaufmann et al., 2009; Rasoulkhani et al., 2018; Wang et al., 2018; Zhang \& Nuttall, 2011).

\subsubsection{Network-centric analysis}

Network-centric analysis, on the other hand, is applicable for questions where agent properties can be kept constant and the focus is on the impact of modifications on the network level. This can be induced by varying link properties or global network measures (such as density or size, see stylized example in Figure 3b) or by a comparison of different network topologies. In contrast to modifications at the agent level, these changes affect the network as a whole. Global network measures map network properties to a single value (Araújo \& Banisch, 2016), thus modifying them also changes the entire network. SNA provides several metrics at this level such as network density (Chica et al., 2018; Growiec et al., 2018; Kaufmann et al., 2009; Phan \& Godes, 2018) and size (Chen et al., 2012; Janssen \& Jager, 2001; Ke et al., 2008; Laifa et al., 2018) or the rewiring probability in smallworld networks (Baggio \& Hillis, 2018; Bohlmann et al., 2010; Janssen \& Jager, 2001, 2003). In addition, the global clustering coefficient, network diameter and average path length fall under this category. For the comparison of network topologies, model outcomes emerge based on different network structures such as scale-free, small-world or regular networks (Bohlmann et al., 2010; Bravo et al., 2012; Chen et al., 2012; Chica et al., 2018; Erdlenbruch \& Bonte, 2018; Fu et al., 2011; Hadzibeganovic et al., 2018; Heinrich, 2018; Huétink et al., 2010; Janssen \& Jager, 2003; Ke et al., 2008; Keijzer et al., 2018; Lu et al., 2009; Moglia et al., 2018; Negahban \& Smith, 2018; Rasoulkhani et al., 2018; Schlaile et al., 2018). Changes in link properties include strength (Goldenberg et al., 2007) and direction of social interaction (Flache \& Macy, 2011).

\subsubsection{Structurally explicit analysis}

Both agent- and network-centric analysis methods capture the network as a way to connect agents, but do not address its internal characteristics. The third approach, a structurally explicit analysis, allows a shift to a more causal relation between agents and network structure (Bodin et al., 2011). Here, SNA is applied at the local level to determine the association between the state of the agents and their location in the network. This approach goes beyond the mere combination of agent- and network-centric analysis. The network is not evaluated separately, but directly associated with the properties of agents. Network metrics that can be considered from this perspective are for example degree distribution, local clustering and centrality measures. These local network measures provide information about the relative position to other agents, the importance of specific agents or the existence of subgroups. The stylized example in Figure $3 c$ shows the initial condition for an innovation to spread for two different scenarios with either a highly or a loosely connected agent as innovator. With insights into the correlation between network and agents, implications of the network structure on human behaviour and vice versa can be sensibly addressed. In comparison to network-centric analysis, this allows a targeted modification of both network and model rules to compare the results of different scenarios. Agents can be selected and manipulated not only according to their properties, but also depending on their position in the network.

An example that underlines this advantage is given in the context of models dealing with diffusion in networks. The position of the seed, i.e. depending on the context the first infected or convinced agents, strongly influences model outcomes, as the number and type of contacts of the selected agents can increase or decrease the dissemination. Although there exists an extensive theoretical background on this aspect in social network sciences (Borgatti, 2006; Freeman, 1979; Friedkin, 1991), we observed that in ABM the choice of specific key players based on network properties is often undervalued. In most models the set of actors from which a diffusion starts to propagate is selected randomly or according to agent-centric properties such as personality. Table 2 is based on the few examples among the articles in the literature review where common network measures have been used to determine individuals selected as first adopters of an innovation or technology (Beretta et al., 2018; Haenlein \& Libai, 2013; Hu et al., 2018; Libai et al., 2013; Negahban \& Smith, 2018).

\subsubsection{Recommendations}

In our evaluation, we observed that the use of agent- and network-centric analysis methods is widespread. However, the application of SNA at the local level to gain insights into the relation between network structure and agent properties is the exception. Examples for specifically targeted selection of first adopters were found only in models in the context of product or technology diffusion (Table 2), although this issue is also relevant for the dissemination of knowledge or information in social systems or with respect to epidemic diffusion. The most 
common approach to assessing model outcomes is to implement various network structures and compare the results under these different assumptions. However, restricting the analysis to a limited set of network metrics that only monitor global properties of networks and omit the full range of SNA at the local level ignores a valuable aspect of the integration of social networks in agent-based models. Depending on the research problem and questions at hand, a structural analysis of the network is not a prerequisite to gain new insights. However, we would like to emphasize the additional benefits of the causal relation between network connections and agent properties and therefore encourage modellers to devote more attention to approach (iii), the structurally explicit analysis.

Table 2: Overview of common network measures for the selection of seeding scenarios, i.e. depending on the context first infected or convinced agents, with application examples among the articles in the literature review where innovation diffusion is studied with ABM

\begin{tabular}{|c|c|c|}
\hline Network measure & Description & References \\
\hline Degree & $\begin{array}{l}\text { Select agents based on their number of neighbours. Select } \\
\text { agents with high degree first. }\end{array}$ & $\begin{array}{l}\text { Haenlein \& Libai (2013); Libai et } \\
\text { al. (2013); Hu et al. (2018); } \\
\text { Negahban \& Smith (2018) }\end{array}$ \\
\hline $\begin{array}{l}\text { Local clustering } \\
\text { coefficient }\end{array}$ & $\begin{array}{l}\text { Select agents based on the number of edges between } \\
\text { neighbouring nodes divided by the total number of } \\
\text { possible edges between neighbouring nodes. Select agents } \\
\text { with low clustering as there is less overlap between the } \\
\text { neighbours. }\end{array}$ & Negahban \& Smith (2018) \\
\hline $\begin{array}{l}\text { Closeness centrality } \\
\text { (average path length) }\end{array}$ & $\begin{array}{l}\text { Select agents based on the average number of steps to } \\
\text { reach any other node in the network. Select agents with } \\
\text { the shortest average path length first. }\end{array}$ & $\begin{array}{l}\text { Beretta et al. (2018); Negahban } \\
\text { \& Smith (2018) }\end{array}$ \\
\hline Betweenness centrality & $\begin{array}{l}\text { Select agents based on the number of times they act as a } \\
\text { bridge along the shortest path between two other nodes. } \\
\text { Select agents with the highest betweenness centrality first. }\end{array}$ & Beretta et al. (2018) \\
\hline Eigenvector centrality & $\begin{array}{l}\text { Select agents based on the centrality of their neighbours. } \\
\text { The eigenvector centrality is higher the more central the } \\
\text { neighbouring agents are. Select agents with the highest } \\
\text { eigenvector centrality first. }\end{array}$ & Beretta et al. (2018) \\
\hline
\end{tabular}

\subsection{Condensed classification of models included in the review}

Table 3 classifies all models evaluated in the review according to the types of analysis and the context of application (see Supplementary Material B for the corresponding references). It is clearly visible that most of the reviewed models focus on agent- or network centric analysis or a combination of both methods. Within the subset of studies we analysed for the review, structurally explicit analysis was found only in models in the context of marketing. Only one of the selected publications managed to combine all three methods: to evaluate the optimal combination of seeding and inventory build-up policies for new products, Negahban and Smith (2018) compared the effect of different strategies of initial dissemination, build-up periods before a product is launched and stylized network structures on adoption rates. In general, this overview provides a good starting point for a transfer of concepts between disciplines, as it facilitates seeing what has been successfully applied in one discipline and what is missing in others. We would like to stress that none of the categories is superior to the others. It is essential to consider the degree of feedback between network structure and agent states and the research questions that the model should address in order to make an informed decision about the appropriate levels of network integration and analysis. 


\begin{tabular}{|c|c|c|c|c|c|c|c|c|c|c|c|c|}
\hline & 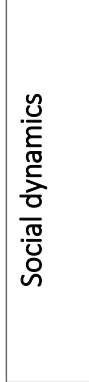 & 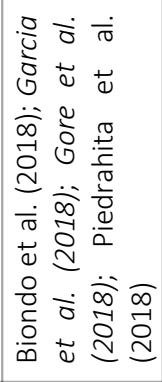 & 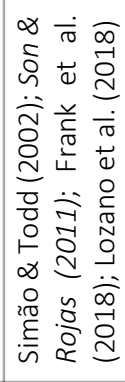 & 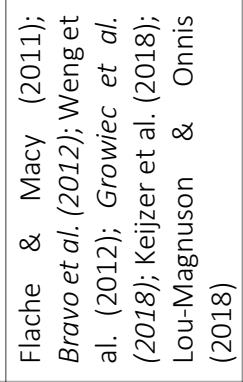 & 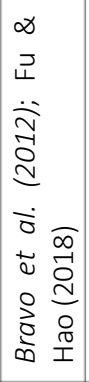 & & 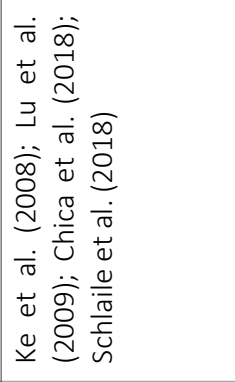 & 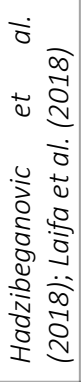 & & & & 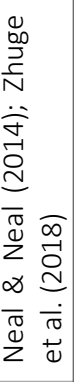 \\
\hline 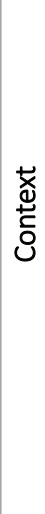 & 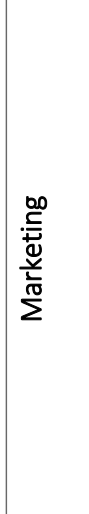 & 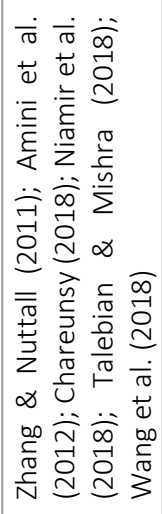 & & 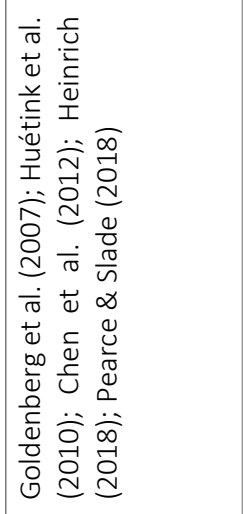 & & 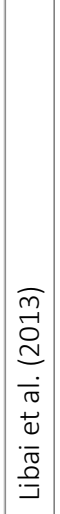 & 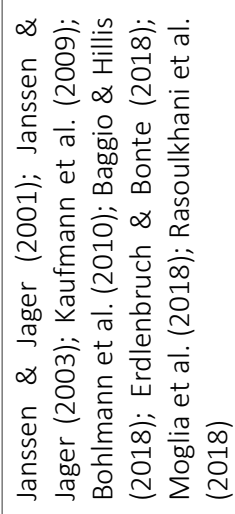 & 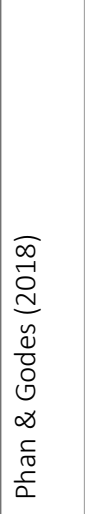 & $\mid$ & 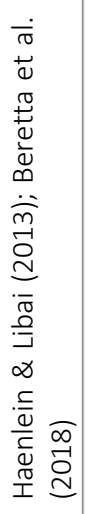 & 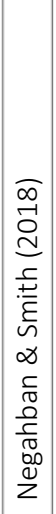 & \\
\hline & 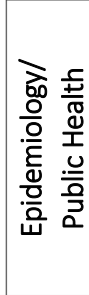 & 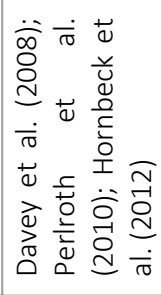 & 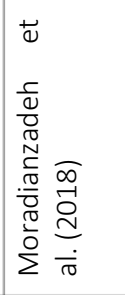 & & & & 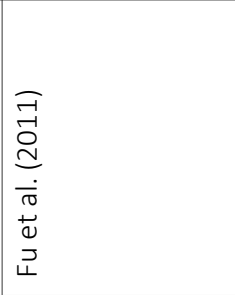 & & & & & 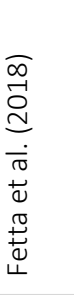 \\
\hline 음 & ن & & $>$ & & $>$ & & & $>$ & & & & \\
\hline 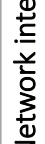 & مَّ & $>$ & & $>$ & & $>$ & $>$ & & $>$ & $>$ & $>$ & \\
\hline & 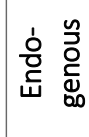 & & & & & & & & & & & $>$ \\
\hline & 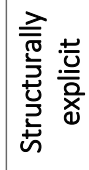 & & & & & $>$ & & & $>$ & $>$ & $>$ & \\
\hline$\frac{\frac{n}{50}}{\frac{10}{00}}$ & 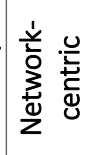 & & & $>$ & & & $>$ & & & $>$ & $>$ & \\
\hline & 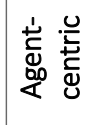 & $>$ & & & & & $>$ & & $>$ & & $>$ & \\
\hline
\end{tabular}




\section{Conceptualization and documentation of social networks in agent-based models}

When implementing social networks in agent-based models, several decisions have to be made about the structure and character of the network and the interaction of agents on it. As these choices decisively influence the model outcome, model conceptualization and documentation are crucial to make the modelling process transparent and reproducible. However, on the basis of our literature review, we observed, on the one hand, that the reasoning behind the choice of certain network topologies and network properties is often based on ad hoc assumptions, not on insights from the broad field of social network research. On the other hand, the model and in particular the network and the interactions on it are often not sufficiently documented. Similar aspects have been criticized in reviews with regard to the operationalization of decision making in agent-based models (Crooks et al., 2008; Flache et al., 2017; Groeneveld et al., 2017; Janssen, 2017; Kiesling et al., 2012; Müller et al., 2013). We build on the solutions to overcome the problems proposed in these studies and focus on (i) incorporating theoretical and empirical insights in the process of model conceptualization and (ii) guidelines as a basis for comprehensive and clearly structured model set-up and evaluation.

\subsection{Incorporating theoretical and empirical insights}

Modelling precisely how agents are linked is an essential task when integrating social networks in ABM (Amblard et al., 2015; Klabunde \& Willekens, 2016). Inspired by empirical studies, a multitude of theoretical network topologies have been developed that allow an informed decision on the choice of suitable networks and their characteristics (Newman, 2003). Because of the variety of options available, the reasoning behind each choice of topology is particularly important (Amblard et al., 2015; Cointet \& Roth, 2007; Zacharias et al., 2008). A thorough analysis of the impact of the underlying topology on the model outcome, which can then be tested with $A B M$, is required. Only when these considerations are made in advance, a meaningful conclusion can be drawn from the results. Additionally, hypotheses about the behaviour of humans in networks such as homophily (i.e. the tendency to form links with similar others), reciprocity (i.e. the number of reciprocated ties of an actor) or transitivity (i.e. friends of friends become friends), which can be drawn from empirical studies, should be integrated in the process of model design (Snijders et al., 2010). The inclusion of knowledge from empirical network research in the decision making of agents on the network is necessary to enable an adequate representation of the co-evolution of networks and behaviour.

\subsection{Guidelines for model set-up and evaluation}

Hand in hand with a sound justification of decisions made for the model conceptualization goes a precise documentation of the model (Grimm et al., 2006; Rand \& Rust, 2011; Schmolke et al., 2010). The choice of a particular network model and the corresponding properties for the interaction of agents need to be substantiated in the model documentation to ensure comprehensibility, comparability and replicability of models which highly strengthens the advancement of the method and its use. We summarize the main aspects that need to be considered for agent-based models combined with social networks in guidelines which can easily be integrated in existing standards for the description of agent-based models, such as the ODD protocol (Grimm et al., 2006, 2010) or its extension concerning the integration of decision making, the ODD+D protocol (Müller et al., 2013). Following the categories of these formats, networks can, for example, be listed as state variables and referred to when specifying the design concepts "Interactions" and "Collectives". Our proposed guidelines are divided into three main categories: network definition, dynamics of the network, and dynamics on the network. The first section covers different aspects of complexity concerning the set-up of nodes and links and network initialization. The two remaining sections focus on the co-evolution of networks and agents and comprise dynamics of and on the network (Gross \& Blasius, 2008). Dynamics of the network cover the network itself as a dynamic system that changes according to specific rules. This section introduces the rules to be described when modifying the topology. Dynamics on the network deal with the dynamically changing state of each node, and comprise the conditions for interactions between agents, the interaction direction and the choice of interaction partners as well as the state transition of the agents and are thus only relevant for exogenously imposed and co-evolutionary networks.

The guidelines with the main principles that need to be considered for model set-up and documentation are presented in Box 1. Modellers intending to design a model with endogenously emerging networks need to focus specifically on the section on the dynamics of the network. For models with exogenously imposed networks, the 
section on the dynamics on the networks is most applicable. In models with co-evolutionary networks, all sections must be considered. Careful reflection and justification of all relevant aspects of the guidelines during the model building process provides a solid foundation for analysis. The guidelines ensure that all variables that can be investigated with an agent- or network-centric sensitivity analysis are properly introduced. In addition, it is particularly useful when local network metrics are evaluated in a structurally explicit analysis.

Box 1: Guidelines for improved model set-up and documentation

i. Network definition

a. Nodes

Level of aggregation: What is represented by an agent (c.f. "Collectives" in ODD design concepts)?

The chosen subdivision that represents interacting partners has crucial influence on the network (Levin, 1992). Subdivisions depend on the level of decision making or action and the required level of accuracy but are limited by computational power (number of interacting agents grows fast if low level of aggregation is chosen). Possible subdivisions are:

- Individual agents: used in situations where the personal context is relevant (e.g. epidemics, opinion formation)

- Households: aggregated behaviour of family members or relevant decisions made by household head (e.g. landuse context: farmers, energy consumption: data availability on household level)

- $\quad$ Firms: similar to households but no relation to family (e.g. marketing: product diffusion can be either on individual or on firm level)

- $\quad$ Higher level of aggregation possible (e.g. regions, countries)

Typology of agents: Which entities are grouped together and treated in a similar manner?

Within the levels of aggregation, agents are grouped according to their attributes to allow generalizations of individual actors (Arneth et al., 2014). This includes classification on the same organisational level with same (e.g. green vs. conventional farmers, early vs. late adopters) and different functions (e.g. buyers vs. sellers) or across hierarchical organisational scales (e.g. land users vs. government).

b. Links

Reciprocity: Are the links directed or undirected?

Some problems need reciprocal links, some can deal with both but are probably more realistic with either directed or undirected links (opinion diffusion sometimes modelled in directed networks, sometimes in undirected), some need directed links (e.g. material transfer often only in one direction).

Weight: Do the links include weighted relationships and preferences?

Link strength allows including weighted relationships and preferences among neighbours. Link strength can be discrete (e.g. strong/weak) or continuous (assigning relative or absolute weights to links) and can be determined by the number of common contacts or emotional intensity such as trust or similarity of opinions.

c. Initialization

Initial condition: Which links are present as initial conditions?

The network formation can start from scratch with no links between the nodes established at the beginning of the simulation or with links set up according to a specified topology.

Network topology: How are initial links motivated?

If links are set up according to a specified topology, initial network topologies can be calibrated with empirical data or with idealized topologies (e.g. random, small-world or scale-free).

\section{ii. Dynamics of the network}

Link formation: Why are links formed between agents?

The formation of links between agents can be based on agent properties (e.g. spatial proximity or similarity), probability, utility maximization, etc.

Network size: Does the number of nodes in the network vary during the simulation?

Network size can be static if the network consists of the same nodes over the whole simulation or dynamic if the nodes vanish or appear during the simulation (e.g. due to extinction and reproduction processes or migration).

\section{iii. Dynamics on the network}

Condition for interaction: When do agents interact?

In some contexts, interaction takes place independent of the network. Thus, no condition on the interaction is needed (e.g. if influence of social norms is always present). Alternatively, a threshold (e.g. number of neighbours, fraction of neighbours, distance (spatially or between opinions), properties of neighbours etc.) has to be reached before the agents interact (Granovetter, 1978).

Interaction direction and partners: Who do agents interact with?

The interaction direction has a large effect on the dynamics on the network as it influences the direction of causality and therefore the relevance of the positions of the agents. The acting agent can either be influenced by the agents in its network ("in", unidirectional) or influence other agents it has links to ("out", unidirectional). Additionally, both agents can change 
their status based on the interaction ("both", bidirectional). The acting agent can either pick one ("pairwise"), several ("selected") or all other agents of its network as interaction partners.

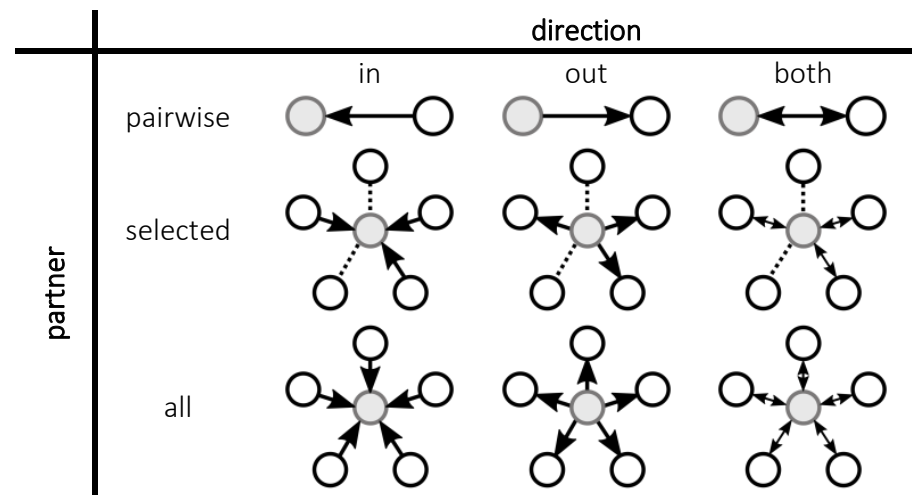

Agent state transition: How do agents change their status?

Change of agent state is influenced by processes like e.g. imitation or averaging or based on probability, distance, utility, etc. The representation of agent state (i.e. behaviour, opinion, health condition etc.) is possible either as continuous traits (e.g. opinions) or distinct nominal categories (e.g. product adoption levels, epidemics). Change of agent state is possible either in one way only (e.g. adoption of an innovation: once somebody has adopted a product he will never come back to the non-adopted state; opinion dynamics: models of assimilative social influence (Flache et al., 2017)) or in two or more ways (e.g. opinion dynamics: models with repulsive influence, opinions can be influenced positively or negatively (Flache et al., 2017; Jager \& Amblard, 2005); epidemiology: agents can get infected but also recover from a disease).

\section{Conclusion}

In this review, we analysed studies in the field of $A B M$ and social networks with a focus on the conditions for sound implementation and evaluation. We stressed that $A B M$ in combination with social networks is a promising approach to address the behaviour of interacting individuals. However, we also indicated that there is room for improvement and offered ways to overcome the deficits. Explicitly, we encourage modellers to improve the integration of the two methods with respect to three main aspects: (1) to not only focus on the network as channels for transfer of material or non-material resources, but also design models where the network provides social integration, such that an agent's network position allows for certain achievements, success or power; (2) to carefully determine the appropriate approach for the integration of social networks in ABM, being it endogenously emerging, exogenously imposed or co-evolutionary, according to the research question at hand, the availability of data but also the relevant time scales of network and agent dynamics; and (3) to devote attention to structurally explicit analysis of the model, i.e. to use local network metrics to gain insights into causal relations between network connections and agent properties.

In addition to these recommendations, we would like to point out that the integration of social networks in agent-based models highly benefits from interdisciplinary exchange. The core themes for the use of networks are similar in different contexts, regardless of the concrete problem they are applied to. Our cross-disciplinary review provides a starting point for this exchange, but is not intended to give a comprehensive overview of all possible realizations. Further efforts are needed to bring together the achievements in different areas and to lower disciplinary barriers that currently hinder a broader transfer of concepts. A systematic documentation of the model conceptualization, as supported by the guidelines, would facilitate this goal by allowing an efficient way of comparing models and their analyses. Additionally, as in many areas of ABM, also with regard to social networks in agent-based models the inclusion of empirical data is a crucial issue (Grimm et al., 2005; Laatabi et al., 2018). For this purpose, the approach of stochastic actor-oriented models is worth to consider. This statistical method is similar to agent-based models in the property to include local rules for actor behaviour and is an established tool for the analysis of longitudinal network data (Snijders et al., 2010; Snijders \& Steglich, 2015). $A B M$ has, however, more opportunities to include environmental constraints and heterogeneity among agents (Bruch \& Atwell, 2015). Calibration of network initialization and validation of model outcomes with empirical data are therefore crucial next steps to fully exploit the potential of ABM. 


\section{Acknowledgements}

We thank Sven Banisch, Thomas Banitz, Volker Grimm, David Kreuer and Till Rockenbauch and two anonymous reviewers for helpful comments on a previous version of this paper. MW was supported by the Deutsche Forschungsgemeinschaft (DFG, German Research Foundation) in the project SEEMI (Social-Ecological Effects of Microinsurance) - 321077328. BM acknowledges funding by the German Federal Ministry of Education and Research (BMBF-01LN1315A) within the Junior Research Group POLISES.

\section{References}

Albert, R., \& Barabási, A.-L. (2002). Statistical mechanics of complex networks. Reviews of Modern Physics, 74(1), 47-97. doi:10.1103/RevModPhys.74.47

Amblard, F., Bouadjio-Boulic, A., Sureda Gutiérrez, C., \& Gaudou, B. (2015). Which models are used in social simulation to generate social networks? A review of 17 years of publications in JASSS. Winter Simulation Conference Proceedings (pp. 4021-4032). doi:10.1109/wsc.2015.7408556

Amini, M., Wakolbinger, T., Racer, M., \& Nejad, M. G. (2012). Alternative supply chain production-sales policies for new product diffusion: An agent-based modeling and simulation approach. European Journal of Operational Research, 216(2), 301-311. doi:10.1016/j.ejor.2011.07.040

Andre, F. E., Booy, R., Bock, H. L., Clemens, J., Datta, S. K., John, T. J., Lee, B. W., Lolekha, S., Peltola, H., Ruff, T. A., Santosham, M., \& Schmitt, H. J. (2008). Vaccination greatly reduces disease, disability, death and inequity worldwide. Bulletin of the World Health Organization, 86(2), 140-146. doi:10.2471/BLT.07.040089

Araújo, T., \& Banisch, S. (2016). Multidimensional Analysis of Linguistic Networks. In A. Mehler, A. Lücking, S. Banisch, P. Blanchard, \& B. Job (Eds.), Towards a Theoretical Framework for Analyzing Complex Linguistic Networks (pp. 107131). Berlin, Heidelberg: Springer Berlin Heidelberg. doi:10.1007/978-3-662-47238-5_5

Arneth, A., Brown, C., \& Rounsevell, M. D. A. (2014). Global models of human decision-making for land-based mitigation and adaptation assessment. Nature Climate Change, 4(7), 550-557. doi:10.1038/nclimate2250

Baggio, J. A., \& Hillis, V. (2018). Managing ecological disturbances: Learning and the structure of social-ecological networks. Environmental Modelling \& Software, 109, 32-40. doi:10.1016/j.envsoft.2018.08.002

Beretta, E., Fontana, M., Guerzoni, M., \& Jordan, A. (2018). Cultural dissimilarity: Boon or bane for technology diffusion? Technological Forecasting and Social Change, 133, 95-103. doi:10.1016/j.techfore.2018.03.008

Bianchi, F., \& Squazzoni, F. (2015). Agent-based models in sociology. Wiley Interdisciplinary Reviews: Computational Statistics, 7(4), 284-306. doi:10.1002/wics.1356

Biondo, A. E., Pluchino, A., \& Rapisarda, A. (2018). Modeling surveys effects in political competitions. Physica A: Statistical Mechanics and its Applications, 503, 714-726. doi:10.1016/j.physa.2018.02.211

Bodin, Ö., Ramirez-Sanchez, S., Ernstson, H., \& Prell, C. (2011). A social relational approach to natural resource governance. In C. Prell \& Ö. Bodin (Eds.), Social Networks and Natural Resource Management: Uncovering the Social Fabric of Environmental Governance (pp. 3-28). Cambridge, UK: Cambridge University Press. doi:10.1017/СBO9780511894985.002

Bohlmann, J. D., Calantone, R. J., \& Zhao, M. (2010). The Effects of Market Network Heterogeneity on Innovation Diffusion: An Agent-Based Modeling Approach. Journal of Product Innovation Management, 27(5), 741-760. doi:10.1111/j.1540-5885.2010.00748.x

Bonabeau, E. (2002). Agent-based modeling: Methods and techniques for simulating human systems. Proceedings of the National Academy of Sciences of the United States of America, 99(suppl 3), 7280-7287. doi:10.1073/pnas.082080899

Borgatti, S. P. (2006). Identifying sets of key players in a social network. Computational \& Mathematical Organization Theory, 12(1), 21-34. doi:10.1007/s10588-006-7084-x

Borgatti, S. P., \& Foster, P. C. (2003). The Network Paradigm in Organizational Research: A Review and Typology. Journal of Management, 29(6), 991-1013. doi:10.1016/S0149-2063_03_00087-4

Borgatti, S. P., Mehra, A., Brass, D. J., \& Labianca, G. (2009). Network Analysis in the Social Sciences. Science, 323(5916), 892895. doi:10.1126/science.1165821

Bravo, G., Squazzoni, F., \& Boero, R. (2012). Trust and partner selection in social networks: An experimentally grounded model. Social Networks, 34(4), 481-492. doi:10.1016/j.socnet.2012.03.001

Bruch, E., \& Atwell, J. (2015). Agent-Based Models in Empirical Social Research. Sociological Methods \& Research, 44(2), 186221. doi:10.1177/0049124113506405

Butts, C. T. (2009). Revisiting the Foundations of Network Analysis. Science, 325(5939), $414-416$. doi:10.1126/science.1171022

Carley, K. M. (2009). Computational modeling for reasoning about the social behavior of humans. Computational \& Mathematical Organization Theory, 15(1), 47-59. doi:10.1007/s10588-008-9048-9

Castellano, C., Fortunato, S., \& Loreto, V. (2009). Statistical physics of social dynamics. Reviews of Modern Physics, 81(2), 591-646. doi:10.1103/RevModPhys.81.591

Chareunsy, A. K. (2018). Diffusion of development initiatives in a southern Lao community: An agent based evaluation. Journal of Asian Economics, 54, 53-68. doi:10.1016/j.asieco.2017.12.004 
Chen, J., Taylor, J. E., \& Wei, H. H. (2012). Modeling building occupant network energy consumption decision-making: The interplay between network structure and conservation. Energy and Buildings, 47, 515-524. doi:10.1016/j.enbuild.2011.12.026

Chica, M., Chiong, R., Kirley, M., \& Ishibuchi, H. (2018). A Networked N-Player Trust Game and Its Evolutionary Dynamics. IEEE Transactions on Evolutionary Computation, 22(6), 866-878. doi:10.1109/TEVC.2017.2769081

Chowell, G., \& Nishiura, H. (2014). Transmission dynamics and control of Ebola virus disease (EVD): a review. BMC Medicine, 12(196). doi:10.1186/s12916-014-0196-0

Cointet, J. P., \& Roth, C. (2007). How Realistic Should Knowledge Diffusion Models Be? Journal of Artificial Societies and Social Simulation, 10(3), 5. Retrieved from http://jasss.soc.surrey.ac.uk/10/3/5.html

Costenbader, E., \& Valente, T. W. (2003). The stability of centrality measures when networks are sampled. Social Networks, 25(4), 283-307. doi:10.1016/S0378-8733(03)00012-1

Crooks, A., Castle, C., \& Batty, M. (2008). Key challenges in agent-based modelling for geo-spatial simulation. Computers, Environment and Urban Systems, 32(6), 417-430. doi:10.1016/j.compenvurbsys.2008.09.004

Cumming, G. S. (2016). Heterarchies: Reconciling Networks and Hierarchies. Trends in Ecology \& Evolution, 31(8), $622-632$. doi:10.1016/j.tree.2016.04.009

Davey, V. J., Glass, R. J., Min, J. H., Beyeler, W. E., \& Glass, L. M. (2008). Effective, Robust Design of Community Mitigation for Pandemic Influenza: A Systematic Examination of Proposed US Guidance. PLoS ONE, 3(7). doi:10.1371/journal.pone.0002606

El-Sayed, A. M., Scarborough, P., Seemann, L., \& Galea, S. (2012). Social network analysis and agent-based modeling in social epidemiology. Epidemiologic Perspectives \& Innovations, 9. doi:10.1186/1742-5573-9-1

Emirbayer, M., \& Goodwin, J. (1994). Network Analysis, Culture, and the Problem of Agency. American Journal of Sociology, 99(6), 1411-1454. doi:10.1086/230450

Erdlenbruch, K., \& Bonte, B. (2018). Simulating the dynamics of individual adaptation to floods. Environmental Science \& Policy, 84, 134-148. doi:10.1016/j.envsci.2018.03.005

Erdős, P., \& Rényi, A. (1959). On random graphs I. Publicationes Mathematicae Debrecen, 6, 290-297. Retrieved from http://www.renyi.hu/p_erdos/Erdos.html\#1959-11

Eubank, S., Guclu, H., Anil Kumar, V. S., Marathe, M. V., Srinivasan, A., Toroczkai, Z., \& Wang, N. (2004). Modelling disease outbreaks in realistic urban social networks. Nature, 429(6988), 180-184. doi:10.1038/nature02541

Fetta, A., Harper, P., Knight, V., \& Williams, J. (2018). Predicting adolescent social networks to stop smoking in secondary schools. European Journal of Operational Research, 265(1), 263-276. doi:10.1016/j.ejor.2017.07.039

Flache, A., \& Macy, M. W. (2011). Small Worlds and Cultural Polarization. Journal of Mathematical Sociology, 35(1-3), 146176. doi:10.1080/0022250X.2010.532261

Flache, A., Mäs, M., Feliciani, T., Chattoe-Brown, E., Deffuant, G., Huet, S., \& Lorenz, J. (2017). Models of Social Influence: Towards the Next Frontiers. Journal of Artificial Societies and Social Simulation, 20(4), 2. doi:10.18564/jasss.3521

Flache, A., \& Snijders, T. A. B. (2008). Die Modellierung komplexer Netzwerke: zum Nutzen agentenbasierter Modelle in der neuen Netzwerkforschung. In K.-S. Rehberg (Ed.), Die Natur der Gesellschaft: Verhandlungen des 33. Kongresses der Deutschen Gesellschaft für Soziologie in Kassel 2006. Teilbd. 1 u. 2 (pp. 781-797). Frankfurt: Campus Verlag. Retrieved from https://nbn-resolving.org/urn:nbn:de:0168-ssoar-153088

Frank, K. A., Xu, R., \& Penuel, W. R. (2018). Implementation of Evidence-Based Practice in Human Service Organizations: Implications from Agent-Based Models. Journal of Policy Analysis and Management, 37(4), 867-895. doi:10.1002/pam.22081

Freeman, L. C. (1979). Centrality in Social Networks Conceptual Clarification. Social Networks, 1(3), $215-239$. doi:10.1016/0378-8733(78)90021-7

Friedkin, N. E. (1991). Theoretical Foundations for Centrality Measures. American Journal of Sociology, 96(6), 1478-1504. doi:10.1086/229694

Fu, F., Rosenbloom, D. I., Wang, L., \& Nowak, M. A. (2011). Imitation dynamics of vaccination behaviour on social networks. Proceedings of the Royal Society B: Biological Sciences, 278(1702), 42-49. doi:10.1098/rspb.2010.1107

Fu, Z., \& Hao, L. (2018). Agent-based modeling of China's rural-urban migration and social network structure. Physica A: Statistical Mechanics and its Applications, 490, 1061-1075. doi:10.1016/j.physa.2017.08.145

Garcia, L. M. T., Roux, A. V. D., Martins, A. C. R., Yang, Y., \& Florindo, A. A. (2018). Exploring the emergence and evolution of population patterns of leisure-time physical activity through agent-based modelling. International Journal of Behavioral Nutrition and Physical Activity, 15(1), 112. doi:10.1186/s12966-018-0750-9

Garlaschelli, D., \& Loffredo, M. I. (2005). Structure and evolution of the world trade network. Physica A: Statistical Mechanics and its Applications, 355(1), 138-144. doi:10.1016/j.physa.2005.02.075

Gereffi, G. (1999). International trade and industrial upgrading in the apparel commodity chain. Journal of International Economics, 48(1), 37-70. doi:10.1016/S0022-1996(98)00075-0

Gilbert, N. (2008). Agent-Based Models. Thousand Oaks, CA: SAGE Publications. doi:10.4135/9781412983259

Goldenberg, J., Libai, B., Moldovan, S., \& Muller, E. (2007). The NPV of bad news. International Journal of Research in Marketing, 24(3), 186-200. doi:10.1016/j.ijresmar.2007.02.003

Goldstone, R. L., \& Janssen, M. A. (2005). Computational models of collective behavior. Trends in Cognitive Sciences, 9(9), 424-430. doi:10.1016/j.tics.2005.07.009

Gore, R. J., Lemos, C., Shults, F. L., \& Wildman, W. (2018). Forecasting Changes in Religiosity and Existential Security with an Agent-Based Model. Journal of Artificial Societies and Social Simulation, 21(1), 4. doi:10.18564/jasss.3596 
Granovetter, M. (1978). Threshold Models of Collective Behavior. American Journal of Sociology, 83(6), 1420-1443. doi:10.1086/226707

Granovetter, M. (1985). Economic Action and Social Structure: The Problem of Embeddedness. American Journal of Sociology, 91(3), 481-510. doi:10.1086/228311

Granovetter, M. (2005). The Impact of Social Structure on Economic Outcomes. Journal of Economic Perspectives, 19(1), 3350. doi:10.1257/0895330053147958

Grimm, V., Berger, U., Bastiansen, F., Eliassen, S., Ginot, V., Giske, J., Goss-Custard, J., Grand, T., Heinz, S. K., Huse, G., Huth, A., Jepsen, J. U., Jørgensen, C., Mooij, W. M., Müller, B., Pe'er, G., Piou, C., Railsback, S. F., Robbins, A. M., Robbins, M. M., Rossmanith, E., Rüger, N., Strand, E., Souissi, S., Stillman, R. A., Vabø, R., Visser, U., \& DeAngelis, D. L. (2006). A standard protocol for describing individual-based and agent-based models. Ecological Modelling, 198(1-2), 115126. doi:10.1016/j.ecolmodel.2006.04.023

Grimm, V., Berger, U., DeAngelis, D. L., Polhill, J. G., Giske, J., \& Railsback, S. F. (2010). The ODD protocol: A review and first update. Ecological Modelling, 221(23), 2760-2768. doi:10.1016/j.ecolmodel.2010.08.019

Grimm, V., Revilla, E., Berger, U., Jeltsch, F., Mooij, W. M., Railsback, S. F., Thulke, H.-H., Weiner, J., Wiegand, T., \& DeAngelis, D. L. (2005). Pattern-Oriented Modeling of Agent-Based Complex Systems: Lessons from Ecology. Science, 310(5750), 987. doi:10.1126/science.1116681

Groeneveld, J., Müller, B., Buchmann, C. M., Dressler, G., Guo, C., Hase, N., Hoffmann, F., John, F., Klassert, C., Lauf, T., Liebelt, V., Nolzen, H., Pannicke, N., Schulze, J., Weise, H., \& Schwarz, N. (2017). Theoretical foundations of human decisionmaking in agent-based land use models - A review. Environmental Modelling \& Software, 87, 39-48. doi:10.1016/j.envsoft.2016.10.008

Gross, T., \& Blasius, B. (2008). Adaptive coevolutionary networks: a review. Journal of the Royal Society Interface, 5(20), 259271. doi:10.1098/rsif.2007.1229

Growiec, K., Growiec, J., \& Kaminski, B. (2018). Social network structure and the trade-off between social utility and economic performance. Social Networks, 55, 31-46. doi:10.1016/j.socnet.2018.05.002

Hadzibeganovic, T., Stauffer, D., \& Han, X. P. (2018). Interplay between cooperation-enhancing mechanisms in evolutionary games with tag-mediated interactions. Physica A: Statistical Mechanics and its Applications, 496, 676-690. doi:10.1016/j.physa.2017.12.113

Haenlein, M., \& Libai, B. (2013). Targeting Revenue Leaders for a New Product. Journal of Marketing, 77(3), 65-80. doi:10.1509/jm.11.0428

Heinrich, T. (2018). A Discontinuity Model of Technological Change: Catastrophe Theory and Network Structure. Computational Economics, 51(3), 407-425. doi:10.1007/s10614-016-9609-9

Hornbeck, T., Naylor, D., Segre, A. M., Thomas, G., Herman, T., \& Polgreen, P. M. (2012). Using Sensor Networks to Study the Effect of Peripatetic Healthcare Workers on the Spread of Hospital-Associated Infections. Journal of Infectious Diseases, 206(10), 1549-1557. doi:10.1093/infdis/jis542

Hu, H. H., Lin, J., Qian, Y. J., \& Sun, J. (2018). Strategies for new product diffusion: Whom and how to target? Journal of Business Research, 83, 111-119. doi:10.1016/j.jbusres.2017.10.010

Huétink, F. J., Vooren, A. V. der, \& Alkemade, F. (2010). Initial infrastructure development strategies for the transition to sustainable mobility. Technological Forecasting and Social Change, 77(8), 1270-1281. doi:10.1016/j.techfore.2010.03.012

Jackson, M. O. (2010). Social and Economic Networks. Princeton, NJ: Princeton University Press. doi:10.2307/j.ctvcm4gh1

Jager, W., \& Amblard, F. (2005). Uniformity, Bipolarization and Pluriformity Captured as Generic Stylized Behavior with an Agent-Based Simulation Model of Attitude Change. Computational \& Mathematical Organization Theory, 10(4), 295303. doi:10.1007/s10588-005-6282-2

Janssen, M. A. (2017). The Practice of Archiving Model Code of Agent-Based Models. Journal of Artificial Societies and Social Simulation, 20(1), 2. doi:10.18564/jasss.3317

Janssen, M. A., \& Jager, W. (2001). Fashions, habits and changing preferences: Simulation of psychological factors affecting market dynamics. Journal of Economic Psychology, 22(6), 745-772. doi:10.1016/S0167-4870(01)00063-0

Janssen, M. A., \& Jager, W. (2003). Simulating Market Dynamics: Interactions between Consumer Psychology and Social Networks. Artificial Life, 9(4), 343-356. doi:10.1162/106454603322694807

Kaplan, A. M., \& Haenlein, M. (2010). Users of the world, unite! The challenges and opportunities of Social Media. Business Horizons, 53(1), 59-68. doi:10.1016/j.bushor.2009.09.003

Kaufmann, P., Stagl, S., \& Franks, D. W. (2009). Simulating the diffusion of organic farming practices in two New EU Member States. Ecological Economics, 68(10), 2580-2593. doi:10.1016/j.ecolecon.2009.04.001

$\mathrm{Ke}$, J., Gong, T., \& Wang, W. S. Y. (2008). Language change and social networks. Communications in Computational Physics, 3(4), 935-949. Retrieved from http://www.global-sci.com/intro/article_detail/cicp/7882.html

Keijzer, M. A., Mas, M., \& Flache, A. (2018). Communication in Online Social Networks Fosters Cultural Isolation. Complexity. doi:10.1155/2018/9502872

Kiesling, E., Günther, M., Stummer, C., \& Wakolbinger, L. M. (2012). Agent-based simulation of innovation diffusion: a review. Central European Journal of Operations Research, 20(2), 183-230. doi:10.1007/s10100-011-0210-y

Kjeldahl, E. M., \& Hendricks, V. F. (2018). The sense of social influence: pluralistic ignorance in climate change. EMBO reports, 19(11). doi:10.15252/embr.201847185

Klabunde, A., \& Willekens, F. (2016). Decision-Making in Agent-Based Models of Migration: State of the Art and Challenges. European Journal of Population, 32(1), 73-97. doi:10.1007/s10680-015-9362-0 
Laatabi, A., Marilleau, N., Nguyen-Huu, T., Hbid, H., \& Ait Babram, M. (2018). ODD+2D: An ODD Based Protocol for Mapping Data to Empirical ABMs. Journal of Artificial Societies and Social Simulation, 21(2), 9. doi:10.18564/jasss.3646

Laifa, M., Akrouf, S., \& Mammeri, R. (2018). Forgiveness and trust dynamics on social networks. Adaptive Behavior, 26(2), 65-83. doi:10.1177/1059712318762733

Levin, S. A. (1992). The Problem of Pattern and Scale in Ecology: The Robert H. MacArthur Award Lecture. Ecology, 73(6), 1943-1967. doi:10.2307/1941447

Libai, B., Muller, E., \& Peres, R. (2013). Decomposing the Value of Word-of-Mouth Seeding Programs: Acceleration versus Expansion. Journal of Marketing Research, 50(2), 161-176. doi:10.1509/jmr.11.0305

Lou-Magnuson, M., \& Onnis, L. (2018). Social Network Limits Language Complexity. Cognitive Science, 42(8), $2790-2817$. doi:10.1111/cogs.12683

Lozano, P., Antonioni, A., Tomassini, M., \& Sánchez, A. (2018). Cooperation on dynamic networks within an uncertain reputation environment. Scientific Reports, 8, 9093. doi:10.1038/s41598-018-27544-5

Lu, Q., Korniss, G., \& Szymanski, B. K. (2009). The Naming Game in social networks: community formation and consensus engineering. Journal of Economic Interaction and Coordination, 4(2), 221-235. doi:10.1007/s11403-009-0057-7

Macy, M. W., \& Willer, R. (2002). From Factors to Actors: Computational Sociology and Agent-Based Modeling. Annual Review of Sociology, 28(1), 143-166. doi:10.1146/annurev.soc.28.110601.141117

Moglia, M., Podkalicka, A., \& McGregor, J. (2018). An Agent-Based Model of Residential Energy Efficiency Adoption. Journal of Artificial Societies and Social Simulation, 21(3), 3. doi:10.18564/jasss.3729

Moradianzadeh, N., Zadeh, P. M., Kobti, Z., Hansen, S., \& Pfaff, K. (2018). Using social network analysis to model palliative care. Journal of Network and Computer Applications, 120, 30-41. doi:10.1016/j.jnca.2018.07.004

Müller, B., Bohn, F., Dreßler, G., Groeneveld, J., Klassert, C., Martin, R., Schlüter, M., Schulze, J., Weise, H., \& Schwarz, N. (2013). Describing human decisions in agent-based models - ODD + D, an extension of the ODD protocol. Environmental Modelling \& Software, 48, 37-48. doi:10.1016/j.envsoft.2013.06.003

Namatame, A., \& Chen, S. H. (2016). Agent-Based Modeling and Network Dynamics. Oxford, UK: Oxford University Press. doi:10.1093/acprof:oso/9780198708285.001.0001

Neal, Z. P., \& Neal, J. W. (2014). The (In)compatibility of Diversity and Sense of Community. American Journal of Community Psychology, 53(1-2), 1-12. doi:10.1007/s10464-013-9608-0

Negahban, A., \& Smith, J. S. (2018). A joint analysis of production and seeding strategies for new products: an agent-based simulation approach. Annals of Operations Research, 268(1-2), 41-62. doi:10.1007/s10479-016-2389-8

Newman, M. E. J. (2003). The Structure and Function of Complex Networks. SIAM Review, 45(2), 167-256. doi:10.1137/S003614450342480

Niamir, L., Filatova, T., Voinov, A., \& Bressers, H. (2018). Transition to low-carbon economy: Assessing cumulative impacts of individual behavioral changes. Energy Policy, 118, 325-345. doi:10.1016/j.enpol.2018.03.045

Pastor-Satorras, R., \& Vespignani, A. (2001). Epidemic Spreading in Scale-Free Networks. Physical Review Letters, 86(14), 3200-3203. doi:10.1103/PhysRevLett.86.3200

Pearce, P., \& Slade, R. (2018). Feed-in tariffs for solar microgeneration: Policy evaluation and capacity projections using a realistic agent-based model. Energy Policy, 116, 95-111. doi:10.1016/j.enpol.2018.01.060

Peres, R., Muller, E., \& Mahajan, V. (2010). Innovation diffusion and new product growth models: A critical review and research directions. International Journal of Research in Marketing, 27(2), 91-106. doi:10.1016/j.ijresmar.2009.12.012

Perlroth, D. J., Glass, R. J., Davey, V. J., Cannon, D., Garber, A. M., \& Owens, D. K. (2010). Health Outcomes and Costs of Community Mitigation Strategies for an Influenza Pandemic in the United States. Clinical Infectious Diseases, 50(2), 165-174. doi:10.1086/649867

Phan, T. Q., \& Godes, D. (2018). The Evolution of Influence Through Endogenous Link Formation. Marketing Science, 37(2), 259-278. doi:10.1287/mksc.2017.1077

Piedrahita, P., Borge-Holthoefer, J., Moreno, Y., \& Gonzalez-Bailon, S. (2018). The contagion effects of repeated activation in social networks. Social Networks, 54, 326-335. doi:10.1016/j.socnet.2017.11.001

Rahmandad, H., \& Sterman, J. (2008). Heterogeneity and Network Structure in the Dynamics of Diffusion: Comparing AgentBased and Differential Equation Models. Management Science, 54(5), 998-1014. doi:10.1287/mnsc.1070.0787

Rai, V., \& Henry, A. D. (2016). Agent-based modelling of consumer energy choices. Nature Climate Change, 6(6), 556-562. doi:10.1038/nclimate2967

Railsback, S. F., \& Grimm, V. (2012). Agent-Based and Individual-Based Modeling: A Practical Introduction. Princeton, NJ: Princeton University Press. Retrieved from https://press.princeton.edu/titles/9639.html

Rand, W., \& Rust, R. T. (2011). Agent-based modeling in marketing: Guidelines for rigor. International Journal of Research in Marketing, 28(3), 181-193. doi:10.1016/j.ijresmar.2011.04.002

Rasoulkhani, K., Logasa, B., Reyes, M. P., \& Mostafavi, A. (2018). Understanding Fundamental Phenomena Affecting the Water Conservation Technology Adoption of Residential Consumers Using Agent-Based Modeling. Water, 10(8). doi:10.3390/w10080993

Rockenbauch, T., \& Sakdapolrak, P. (2017). Social networks and the resilience of rural communities in the Global South: a critical review and conceptual reflections. Ecology and Society, 22(1). doi:10.5751/ES-09009-220110

Schlaile, M. P., Knausberg, T., Mueller, M., \& Zeman, J. (2018). Viral ice buckets: A memetic perspective on the ALS Ice Bucket Challenge's diffusion. Cognitive Systems Research, 52, 947-969. doi:10.1016/j.cogsys.2018.09.012 
Schmolke, A., Thorbek, P., DeAngelis, D. L., \& Grimm, V. (2010). Ecological models supporting environmental decision making: a strategy for the future. Trends in Ecology \& Evolution, 25(8), 479-486. doi:10.1016/j.tree.2010.05.001

Scott, J. (2011). Social network analysis: developments, advances, and prospects. Social Network Analysis and Mining, 1(1), 21-26. doi:10.1007/s13278-010-0012-6

Senbel, M., Ngo, V. D., \& Blair, E. (2014). Social mobilization of climate change: University students conserving energy through multiple pathways for peer engagement. Journal of Environmental Psychology, 38, 84-93. doi:10.1016/j.jenvp.2014.01.001

Simão, J., \& Todd, P. M. (2002). Modeling Mate Choice in Monogamous Mating Systems with Courtship. Adaptive Behavior, 10(2), 113-136. doi:10.1177/1059-712302-010002-03

Smith, K. P., \& Christakis, N. A. (2008). Social Networks and Health. Annual Review of Sociology, 34(1), 405-429. doi:10.1146/annurev.soc.34.040507.134601

Snijders, T. A. B., Bunt, G. G. van de, \& Steglich, C. E. G. (2010). Introduction to stochastic actor-based models for network dynamics. Social Networks, 32(1), 44-60. doi:10.1016/j.socnet.2009.02.004

Snijders, T. A. B., \& Steglich, C. E. G. (2015). Representing Micro-Macro Linkages by Actor-based Dynamic Network Models. Sociological Methods \& Research, 44(2), 222-271. doi:10.1177/0049124113494573

Son, J., \& Rojas, E. M. (2011). Evolution of Collaboration in Temporary Project Teams: An Agent-Based Modeling and Simulation Approach. Journal of Construction Engineering and Management, 137(8), 619-628. doi:10.1061/(ASCE)CO.1943-7862.0000331

Squazzoni, F. (2010). The Impact of Agent-Based Models in the Social Sciences after 15 Years of Incursions. History of Economic Ideas, 18(2), 197-233. Retrieved from http://www.jstor.org/stable/23723517

Squazzoni, F., Jager, W., \& Edmonds, B. (2014). Social Simulation in the Social Sciences: A Brief Overview. Social Science Computer Review, 32(3), 279-294. doi:10.1177/0894439313512975

Stumpf, M. P. H., Wiuf, C., \& May, R. M. (2005). Subnets of scale-free networks are not scale-free: Sampling properties of networks. Proceedings of the National Academy of Sciences of the United States of America, 102(12), 4221-4224. doi:10.1073/pnas.0501179102

Talebian, A., \& Mishra, S. (2018). Predicting the adoption of connected autonomous vehicles: A new approach based on the theory of diffusion of innovations. Transportation Research Part C: Emerging Technologies, 95, 363-380. doi:10.1016/j.trc.2018.06.005

Valente, T. W. (2005). Network Models and Methods for Studying the Diffusion of Innovations. In P. J. Carrington, J. Scott, \& S. Wasserman (Eds.), Models and Methods in Social Network Analysis, Structural Analysis in the Social Sciences (pp. 98-116). Cambridge, UK: Cambridge University Press. doi:10.1017/CBO9780511811395.006

Verelst, F., Willem, L., \& Beutels, P. (2016). Behavioural change models for infectious disease transmission: a systematic review (2010-2015). Journal of the Royal Society Interface, 13(125). doi:10.1098/rsif.2016.0820

Walker, B. H., Carpenter, S. R., Rockstrom, J., Crépin, A.-S., \& Peterson, G. D. (2012). Drivers, "Slow" Variables, "Fast" Variables, Shocks, and Resilience. Ecology and Society, 17(3). doi:10.5751/es-05063-170330

Wang, G., Zhang, Q., Li, Y., \& Li, H. L. (2018). Policy simulation for promoting residential PV considering anecdotal information exchanges based on social network modelling. Applied Energy, 223, 1-10. doi:10.1016/j.apenergy.2018.04.028

Wasserman, S., \& Faust, K. (1994). Social Network Analysis: Methods and Applications. Cambridge, UK: Cambridge University Press. doi:10.1017/cbo9780511815478

Watts, D. J., \& Strogatz, S. H. (1998). Collective dynamics of 'small-world' networks. Nature, 393(6684), 440-442. doi:10.1038/30918

Weng, L., Flammini, A., Vespignani, A., \& Menczer, F. (2012). Competition among memes in a world with limited attention. Scientific Reports, 2, 335. doi:10.1038/srep00335

Zacharias, G. L., MacMillan, J., \& Van Hemel, S. B. (2008). Behavioral Modeling and Simulation: From Individuals to Societies. (G. L. Zacharias, J. MacMillan, \& S. B. Van Hemel, Eds.). Washington, D.C.: The National Academies Press. doi:10.17226/12169

Zhang, T., \& Nuttall, W. J. (2011). Evaluating Government's Policies on Promoting Smart Metering Diffusion in Retail Electricity Markets via Agent-Based Simulation. Journal of Product Innovation Management, 28(2), 169-186. doi:10.1111/j.1540-5885.2011.00790.x

Zhuge, C. X., Shao, C. F., \& Wei, B. R. (2018). An Agent-based Spatial Urban Social Network Generator: A Case Study of Beijing, China. Journal of Computational Science, 29, 46-58. doi:10.1016/j.jocs.2018.09.005 